\title{
A Proposal of Secure Session Provider Service over NGN
}

\author{
Tadashi Kaji Non-member (Hitachi, Ltd.) \\ Takahiro Fujishiro Non-member (Hitachi, Ltd.) \\ Seiichi Susaki Non-member (Hitachi, Ltd.) \\ Eri Kawai Non-member (Hitachi, Ltd.) \\ Kazuyoshi Hoshino Non-member (Hitachi, Ltd.) \\ Teruo Higashino Non-member (Osaka University)
}

Keywords : Next Generation Network (NGN), IPsec session, Call Session Control Function (CSCF), Security Association (SA) distribution

In these days, telecom operators have been constructing Next Generation Network (NGN). NGN can provide QoS and security to the communication between its users. However, the security is limited inside NGN. Therefore, when the interconnection between NGN and the Internet will be widely used in near future, it will become an important problem to solve how it protects the communications crossing over NGN and the Internet.

This paper proposes a secure session provider service that protects communications crossing over NGN and the Internet in cooperation with NGN's call session control function (CSCF).

The secure communication provider service protects communications between its users from four threats (Eavesdropping, Modification/Destroy of communication data, Impersonation and Phishing)

To protect from above threats, we designed the secure communication provider service to meet following requirements:

(1) Independency of application protocols

(2) Fast establishment of secure communication session

(3) Confidentiality of communication data

(4) Integrity of communication data

(5) Authentication of the peer

The secure session provider service in this paper is based on the model that a trusted third party (TTP) authenticates the peer on behalf of the user and distributes the key for secure communication session between users.

In this service, the secure session control server ( $\mathrm{sSCP}$ ) acts as TTP in cooperation with NGN's call session control function (CSCF), and provides the IPsec session between its users like user terminals (UTs) and application servers (APs). (Fig. 1)

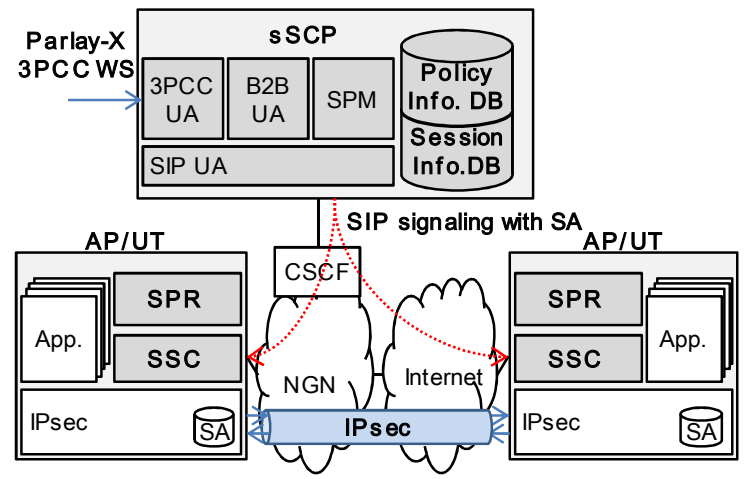

Fig. 1. System architecture
In this service, UTs and APs are authenticated from and registering their security policy into $\mathrm{sSCP}$ by sending SIP MESSAGE messages with their security ability to sSCP at first.

Then, UT requests to sSCP to set up the IPsec session between UT and AP by sending a SIP INVITE message to SSCP or accessing Parlay-X third party call Web service on SSCP.

When $\mathrm{SSCP}$ receives the request from UT, sSCP, sSCP checks if both UT and AP are already authenticated and generates a security association (SA) from registered security policy. Then, SSCP distributes SA to UT and AP via the body of SIP messages.

UT and AP communicate with each other by using SA distributed from sSCP.

(1) The secure session provider service in this paper is independent from application protocols because this service set up and control the IPsec session. (It satisfies the requirement (1))

(2) This service can establish an IPsec session faster than the traditional method (like IKE) because this service performs the peer authentication in prior and omits it when UT request to set up the secure session. (It satisfies the requirements (2) and (5))

(3) This service provides confidentiality and integrity by setting up and controlling the IPsec session via the protected signaling path provided by CSCF. (It satisfies the requirements (3) and (4))

At last, this paper contains the result of " $R \& D$ of fundamental technologies for next generation network (NGN)" funded by NICT, JAPAN.

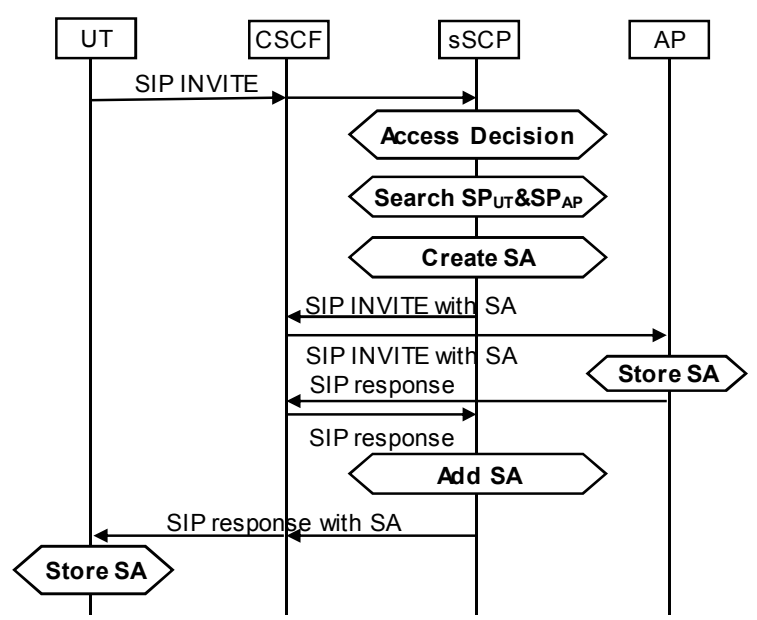

Fig. 2. Session establishment, initiated by SIP INVITE 


\section{NGN を活用したセキュア通信提供サービスの提案}

$\begin{array}{lllll}\text { 非会員 鍛 } & \text { 忠司* } & \text { 非会員 } & \text { 藤城 } & \text { 孝宏* } \\ \text { 非会員 洲崎 } & \text { 誠一 } & \text { 非会員 川井 } & \text { 恵理** } \\ \text { 非会員 星野 } & \text { 和義 } & * & \text { 非会員 東野 } & \text { 輝夫*** }\end{array}$

\section{A Proposal of Secure Session Provider Service over NGN}

Tadashi Kaji*, Non-member, Takahiro Fujishiro*, Non-member, Seiichi Susaki*, Non-member, Eri Kawai**, Non-member, Kazuyoshi Hoshino**, Non-member, Teruo Higashino***, Non-member

In these days, telecom operators in the world have been constructing Next Generation Network (NGN). NGN can provide QoS and security guaranteed communication to its users. However, the protection of communication is limited inside NGN. Therefore, when the interconnection between NGN and the Internet will be widely used in near future, it will become an important problem to solve how it protects the communications crossing over NGN and the Internet.

This paper proposes a secure communication provider service that protects the confidentiality and integrity of communications crossing over NGN and the Internet by setting up and controlling the IPsec session in cooperation with NGN's call session control function (CSCF). In this service, the secure session control provider (sSCP) server and CSCF authenticate its user as Trusted Third Party on behalf of service providers. In addition, this service provides the ability of fast session establishment because sSCP distributes a security association for IPsec session between the user and service provider via the SIP session protected by NGN.

キーワード : 次世代ネットワーク, IPsec セッション, NGN セッション管理機能, SA 配付

Keywords : Next Generation Network (NGN), IPsec session, Call Session Control Function (CSCF), Security Association (SA) distribution

\section{1. はじめに}

現在, 電話網の IP 化と, データ通信・リアルタイム通信・ 放送等の融合を目指した新しいネットワークとして，次世 代ネットワーク（Next Generation Network: NGN）の整備が 進められている。

NGN は, 通信の品質（Quality of Service: QoS）保証とセ キュリティの確保を大きな特徵としている。NGN では, Session Initiation Protocol (SIP) ${ }^{(4)}$ を用いて NGN 上の通信セッ ションを管理・制御することで, ネットワークリソースを 適切に配分し，QoS 保証を実現する。また，NGN では NGN

\footnotetext{
* (株) 日立製作所 システム開発研究所

干244-0817 横浜市戸塚区吉田町 292

Systems Development Lab., Hitachi, Ltd.

292, Yoshida-cho, Totsuka-ku, Yokohama 244-0817

** (株) 日立製作所 ネットワークソリューション事業部

干212-8567 川崎市幸区鹿島田 890

Network Systems Solutions Division, Hitachi, Ltd.

890, Kashimada, Saiwai-ku, Kawasaki 212-8567

*** 大阪大学 大学院情報科学研究科

干 565-0871 大阪府吹田市山田丘 1-5

Graduate School of Information Science and Technology,

Osaka University

1-5, Yamadaoka, Suita, Osaka 565-0871
}

網を保護する機能が仕様策定段階から検討されている(7)(8)。 最近では, NGN のアーキテクチャ, 機能構成要素, プロト コル，セキュリティ管理に関する潜在的な脆弱性の分析や， 悪意を持った正規のユーザによる不正に対するセキュリテ イ対策方針の研究も行われている(9)。また, NGN は中央管 理型のネットワークであるという特徴から NGN 内一の不正 アクセスを防止する方式, 特に, NGN におけるセッション 管理機能（IP Multimedia Subsystem: IMS）に対する研究も進 められている(10)(11)。

上記のように NGN 自体をセキュアにする取り組みと同時 に，NGN は利用者に対してセキュリティが確保された通信 を基本機能として提供することも特徽の一つである。例え ば, NGN では, Network Border Element (NBE) が SIP メッセ ージと連動してセッションが設定された端末間の通信が優 先帯域を利用できるように NBE のピンホールの開閉を行 い, 通信を保護する ${ }^{(1)}$ 。さらに, NGN のサービスの中には, アプリケーションサービスプロバイダ自身が認証サーバを 用意して要求元を認証し, その結果に応じて NGN がネット ワークアクセスを制御するサービスも提供されている( ${ }^{(6)}$ 。

しかし, 現時点では, このような保護は, NGN 内に閉じ 
た通信に限定されており，今後，NGN とインターネットと の相互接続が広く行われるようになると，インターネット に出ていく通信, あるいはインターネットから入ってくる 通信をどのように保護するかが大きな課題となる。

インターネットが広く普及し，セキュリティ上の問題が 顕在化するにしたがって, IPsec ${ }^{(2) や ~ T L S ~}{ }^{(3)}$ といった暗号化通 信プロトコルを用いて通信相手が正しい相手であるかを確 認するとともに，インターネットを流れる通信データを保 護することが一般的となっている。NGN とインターネット の相互接続においても暗号化通信を利用することが有力な 手段であると考えられている。

本稿では, 安心・安全な情報化社会を支える通信基盤と して, 多数の通信装置に対してNGN とインターネットを跨 る通信を保護する暗号化通信セッションを設定・制御する, セキュア通信提供サービスを提案する。

本稿のセキュア通信提供サービスは, セキュアセッショ ン制御サーバ（secure session control provider server: sSCP）が NGN のセッション確立機能 (Call Session Control Function: CSCF）と連携し，SIP を用いて NGN 側とインターネット側 の通信装置の間の暗号化通信セッションを設定・制御する。 特に, 本稿のセキュア通信提供サービスは, 従来のクライ アント・サーバ型通信だけではなく, ファイル共有ソフト ウェアで用いられている, 通信装置同士が通信しあう Peer-to-Peer (P2P) 通信形式にも対応する。

以下， 2 章で, 関連研究について述べ，3 章で，本稿で提 案するセキュア通信提供サービスの適用モデルと要件につ いて述べ, 4 章で, 提案するセキュア通信提供サービスにつ いて概説する。 5 章では提案方式の評価および実装上の考慮 点について述べる。

\section{2. 関連研究 : SIP DIAL-UP}

本稿に関連する研究として, Kawashima らは, NGN と接 続した企業ネットワークや家庭ネットワークに設置された 装置に NGN 側の端末がアクセスを行う場合の SIP DIAL-UP 方式を提案している(5)。

SIP DIAL-UP 方式は, 企業ネットワークや家庭ネットワー クを送受されるデータを保護するため, Internet Key Exchange Protocol (IKE) と IPsec を用いて暗号化通信を行う 場合に, NGN が「SIPを用いてクライアント間に QoS を保 証したUDP セッションを確立」後, アプリケーション間で

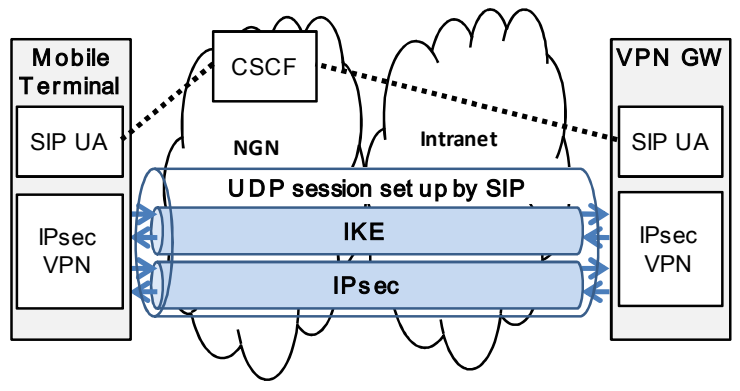

Fig. 1. SIP DIAL-UP
「IKE による鍵交換を行い，VPN セッションを確立」する。

不特定多数の通信装置との間での通信を設定するために SIP DIAL-UP 方式を適用する場合, 次のような課題があると 考えられる。

（1）認証情報の管理

SIP DIAL-UP 方式では, NGN アクセスのための認証情報 に加え, アクセス先毎に（IKE のための）認証情報が必要と なる。SIP DIAL-UP 方式が前提とする, 企業ネットワークや 家庭ネットワークとの間で VPN を確立するような場合に は, アクセス先も単一であるため, 管理すべき認証情報は 高々 2 種類に止まる。しかし, 複数の拠点を持つような大企 業や, P2P 通信アプリケーションに適用しようとすると, ア クセス先の数だけ認証情報を管理しなければならないとい う課題がある。

(2) 通信セッションの確立コスト

SIP DIAL-UP 方式では, SIP によってメディアパスを確立 し, 確立したメディアパス上で鍵交換を実施する。鍵交換 においては，通信相手を認証したり，利用可能な暗号アル ゴリズムのネゴシエーションを行ったりする必要があるた め, セキュアセッションが確立し, アプリケーションデー タの通信が可能になるまでに時間がかかってしまう。特に, 端末同士が通信を相互に行う P2P 通信や, 複数のアプリケ ーションサーバにアクセスを行うサービスマッシュアップ では，ユーザの利便性に大きな影響を与える可能性がある。

\section{3. 適用モデルと機能要件}

〈3·1〉適用モデル＼cjkstart本稿で提案するセキュア通信提 供サービスは, 図 2 に示すように, クライアント・サーバ 通信および P $2 \mathrm{P}$ 通信の 2 つのモデル上の通信を保護する。

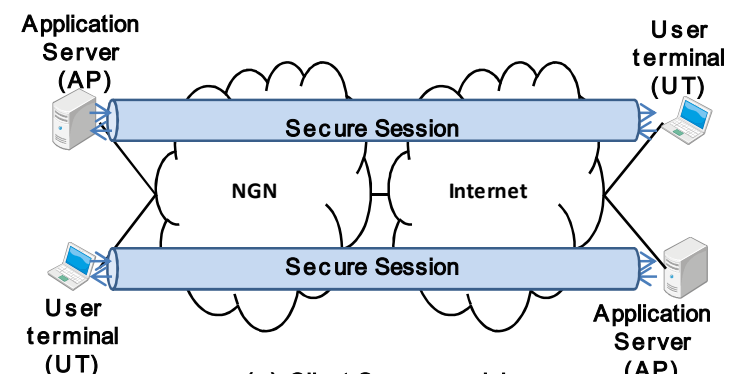

(UT)

(a) Client-Server model

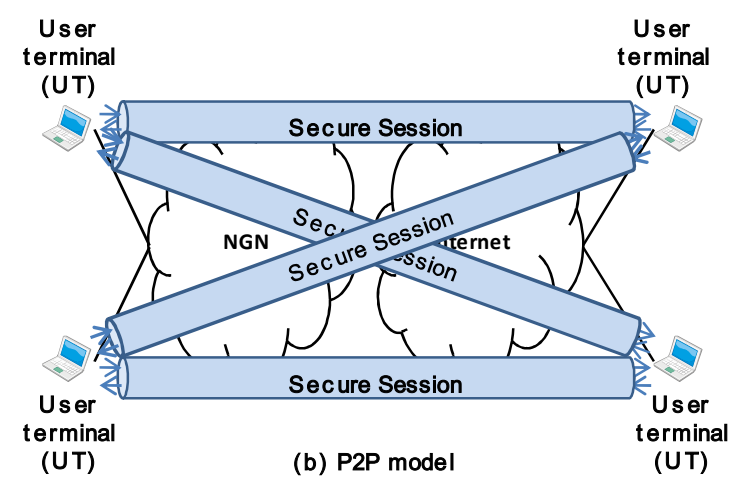

Fig. 2. Application model IEEJ Trans. EIS, Vol.130, No.8, 2010 
クライアント・サーバ通信モデルは，NGN 側のユーザ端 末（UT）とインターネット側のアプリケーションサーバと の間 (AP), およびインターネット側の UT と NGN 側の AP との間の通信を保護する。NGN を利用しているユーザが UT からインターネット側の情報配信サービスを提供する AP にアクセスしたり, 外出しているユーザが UT をインターネ ットに接続してNGNのコンテンツ配信サービスを提供する AP にアクセスしたり, といった場面を想定したモデルであ る。

一方, P2P 通信モデルは, インターネット側および NGN 側に存在する複数の UT が相互に通信しあうモデルである。 ファイル共有サービスや, メッセージングサービス等を想 定したモデルである。

〈3·2〉脅威モデル 上記の適用モデルに対する妿威 として，本稿では次の劦威を想定する。

(1) 通信データの盗聴

(2) 通信データの破壊・改ざん

(3) 成りすましによる通信データの詐取

(4) 不正な通信先への誘導

〈3.3〉 機能要件 上記の適用モデルからセキュア通 信提供サービスが満足すべき, 以下の機能要件を導出した。

(1) アプリケーションプロトコルに非依存であること

NGN とインターネットを跨って行われる通信の形式に は, クライアント・サーバ型通信だけではなく, P2P 通信が 存在する。また，これらの形式のいずれでもアプリケーシ ヨンが使用するアプリケーションプロトコルは多種多様で ある。したがって, セキュア通信提供サービスは, クライ アント・サーバ型通信や P2P 通信といった通信の形式やア プリケーションプロトコルに依存せず，保護を実現できる ことが求められる。

（2）セキュア通信セッションを高速に確立できること

P2P 通信やサービスマッシュアップのように多数の通信 先と通信セッションを確立する必要があるアプリケーショ ンサービスにおいてユーザ利便性への影響を最小化するた め, 高速なセッション確立を実現することが求められる。

さらに, 上記の劦威モデルから，セキュア通信提供サー ビスが満足すべき, 以下の機能要件を導出した。

（3）通信データの機密性を保護する機能

通信データの盗聴を防止するため, 通信データの機密性 を保護する機能が求められる。

(4) 通信データの完全性を検証する機能

通信データの破壊および改ざんを検知するため, 受信し た通信データが通信経路上で編集されていないかを検証す る機能が求められる。

（5）通信先が正当な相手であるかを認証する機能 成りすましによる詐取や不正な通信先への誘導を防止す るため, 通信先を認証する機能が求められる。

\section{NGN を活用したセキュア通信提供サービス}

〈4・1〉概要本章で提案するセキュア通信提供
サービスは，仲介型認証モデル(13) (15)を NGN のセッション 確立機能を用いて実現したものである。

セキュア通信は, 表 1 に示すように, 通信データを保護 するユーザプレーンと，ユーザプレーンを制御する制御プ レーンから構成されている。

仲介型認証モデルでは, 図 3 に示すように, 制御プレー ンを信頼できる第三者（Trusted Third Party: TTP）が制御し, セキュア通信確立に必要な認証処理等を仲介する。特に, 通信の確立要求に先立って TTP が通信相手の認証を代行す ることで, 通信の確立時には認証処理を省略し, セキュア 通信を効率よく確立する。

セキュア通信提供サービスでは, 制御プレーンのプロト コルとして SIP を用い, NGN のセッション確立機能である CSCF とセキュアセッション制御サーバ $(\mathrm{sSCP})$ とが連携し て TTP の役割を果たすことで, NGN とインターネットの相 互接続環境で仲介型認証モデルを実現する（図 4)。

〈4·2〉 セキュア通信提供サービスの動作 図 4 に示 したセキュア通信提供サービスの 5 種類の基本動作をUT が

Table 1. Planes of secure communication

\begin{tabular}{|l|l|}
\hline Plane & Functions \\
\hline User plane & Protection of communication data confidentiality \\
\cline { 2 - 2 } & Protection of communication data integrity \\
\hline \multirow{4}{*}{$\begin{array}{c}\text { Control } \\
\text { plane }\end{array}$} & Peer entity authentication \\
\cline { 2 - 2 } & Authorization (access decision) \\
\cline { 2 - 2 } & Negotiation of security association \\
\cline { 2 - 2 } & Error/Alert notification \\
\cline { 2 - 2 } & Acknowledgement \\
\cline { 2 - 2 } & Revocation of security association \\
\hline
\end{tabular}

TTP

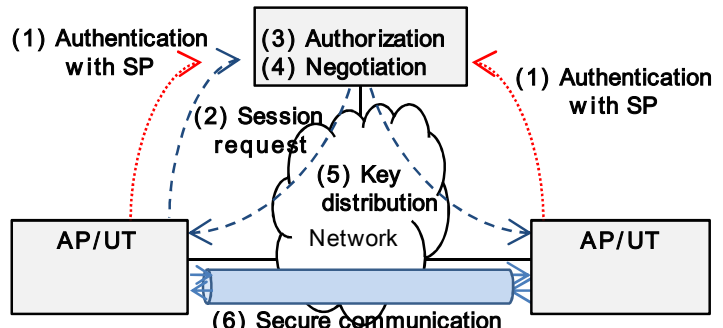

(6) Secure dontmunication

......... $>$ performs only once

$--->$ performs for every session establishment

Fig. 3. Basic concept of proposed service
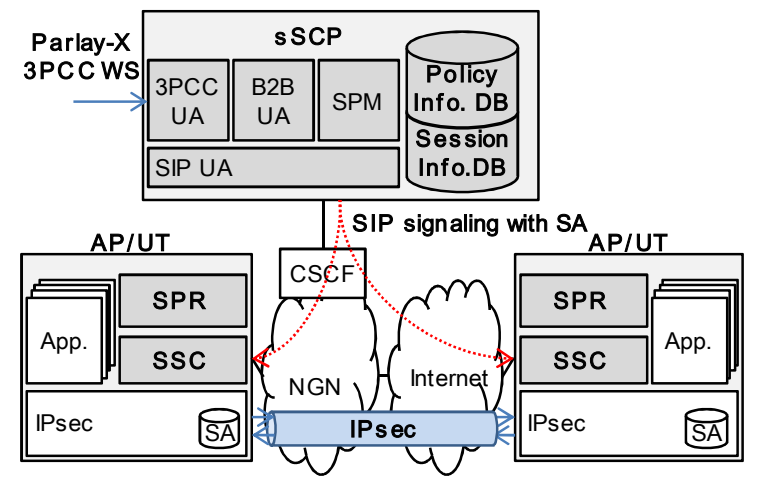

Fig. 4. System architecture 
AP に対して通信を要求する場合を例に説明する。

(1) 認証・セキュリティポリシー登録

仲介認証モデルでは，すべての AP およびUT は，あらゆ る通信に先立って，TTP に認証を受け，TTP にセキュリテ イポリシー（SP）を登録する。

セキュア通信提供サービスでは, 図 5 に示したシーケン スに従って処理を行う。このとき，AP および UT は，SIP MESSAGEメッセージ(18)に表 2 に示すSP を格納して電子署 名を行い，SSCP に送信する。SIP MESSAGEメッセージを 受信した sSCP は，電子署名を検証して SIPメッセージの送 信者を認証する。NGN では, SIP メッセージの送信者詐称 等が行えないため, 以降，同じ送信者（SIP-URI）はすでに 認証済と判断できる。

(2) IPsec 通信セッション確立

仲介認証モデルでは，SPの登録が完了すると，UT は AP と通信を確立することができるようになる。UT が AP と通 信を確立する場合には，TTPにセッション確立要求を送信 し，暗号化通信セッションを設定する。

セキュア通信提供サービスでは, 図 6 に示したシーケン スに従って処理を行う。このとき，セッション確立要求方 法として， sSCP に SIP INVITE メッセージを送信する場合 と, sSCP の Parlay-X Third Party Call Web Service (Parlay-X 3 PCC WS $)^{(16)}$ を利用する場合の 2 種類を提供する。

SIP INVITE メッセージを SSCP に送信する場合, UT は「AP との接続確立を要求する」というメッセージを含む INVITE メッセージを sSCP に送信する。

sSCP はアクセス認可判定を行い, UT が AP と通信する権 限があるかどうかを確認し，UTに通信する権限があれば， UT および AP の SP を検索する。 $\mathrm{SSCP}$ は，2 つの SP から UT および AP の両方で利用可能な Security Association（SA, 表 3 に示す情報から構成される）を作成する。

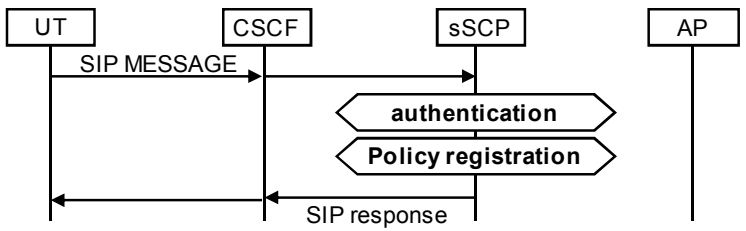

Fig. 5. Authentication \& policy registration

Table 2. Structure of policy information database

\begin{tabular}{|l|l|}
\hline Component & Explanation \\
\hline SIP-URI & $\begin{array}{l}\text { An identifier of the user terminal, assigned } \\
\text { uniquely from the NGN }\end{array}$ \\
\hline IP address & IP address of the user terminal \\
\hline $\begin{array}{l}\text { Encryption } \\
\text { algorithms }\end{array}$ & $\begin{array}{l}\text { A list of encryption algorithms, which the user } \\
\text { terminal can use for IPsec communication } \\
\text { The algorithm is specified in the form } \\
\text { "algorithm name_key length_mode" } \\
\text { (ex. AES_128_CBC) }\end{array}$ \\
\hline $\begin{array}{l}\text { MAC } \\
\text { algorithms }\end{array}$ & $\begin{array}{l}\text { A list of MAC algorithms, which the user } \\
\text { terminal can use for IPsec communication } \\
\text { The algorithm is specified in the form } \\
\text { "algorithm name_key length" } \\
\text { (ex. SHA-1_160) }\end{array}$ \\
\hline
\end{tabular}

次に, SSCP は「UT が接続確立を要求している」という メッセージと SA とを含む SIP INVITEメッセージを作成し て AP に転送する。AP は, SIP INVITEメッセージから SA を取り出して保存すると, SIP 応答メッセージを SSCP に送 信する。SSCP は SIP 応答メッセージを受信すると, UT から 受信した INVITEメッセージに対する応答として, SA を含 むSIP 応答メッセージを作成し, UT に送信する。UT は応 答メッセージから SA を取り出して保存する。

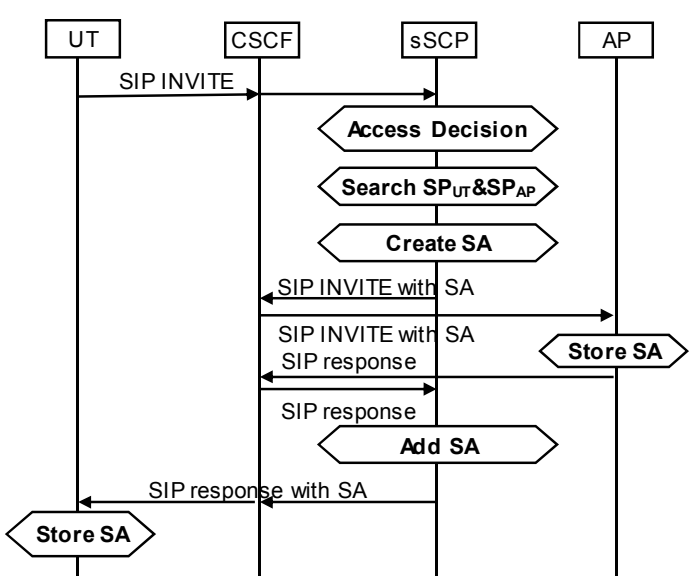

(a) IPsec session establishment, initiated by SIP INVITE message

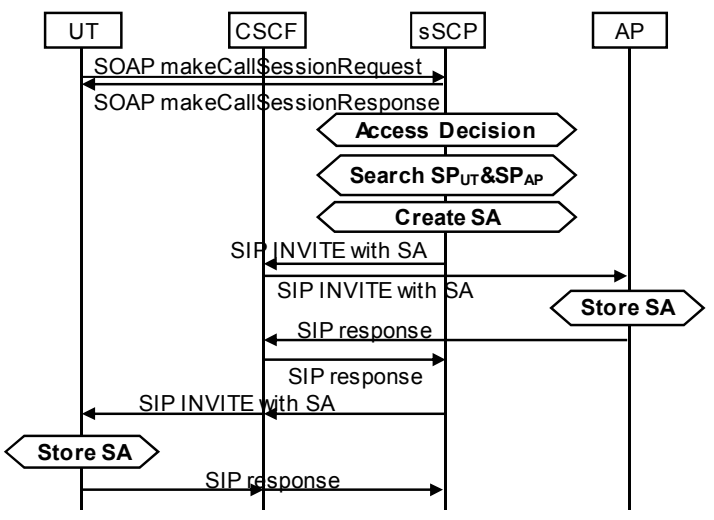

(b) IPsec session establishment, initiated by Paray-XWS

Fig. 6. IPsec session establishment

Table 3. Structure of Security Association

\begin{tabular}{|l|l|}
\hline Component & Explanation \\
\hline SPI & An identifier of this security association \\
\hline $\begin{array}{l}\text { Sender } \\
\text { information }\end{array}$ & $\begin{array}{l}\text { Information in regard to the sender on this } \\
\text { IPsec session, which contains: } \\
\text { - IP address } \\
\text { - port number }\end{array}$ \\
\hline $\begin{array}{l}\text { Receiver } \\
\text { information }\end{array}$ & $\begin{array}{l}\text { Information in regard to the receiver on this } \\
\text { IPsec session, which contains: } \\
\text { - IP address } \\
\text { - port number }\end{array}$ \\
\hline $\begin{array}{l}\text { Encryption } \\
\text { algorithm }\end{array}$ & $\begin{array}{l}\text { Selected encryption algorithm to be used on } \\
\text { this IPsec session }\end{array}$ \\
\hline $\begin{array}{l}\text { Encryption } \\
\text { key }\end{array}$ & $\begin{array}{l}\text { A key value to be used for } \\
\text { encryption/decryption of communication } \\
\text { data on this IPsec session }\end{array}$ \\
\hline $\begin{array}{l}\text { MAC } \\
\text { algorithm }\end{array}$ & $\begin{array}{l}\text { Selected MAC algorithm to be used on this } \\
\text { IPsec session }\end{array}$ \\
\hline Hash key & $\begin{array}{l}\text { A key value to be used for } \\
\text { generation/verification of message } \\
\text { authentication code on this IPsec session }\end{array}$ \\
\hline Validity & Validity period of this security association \\
\hline
\end{tabular}


以上によって, UT と AP の間で SA を共有し, IPsec 通信 セッションが設定される。

一方, Parlay-X 3PCC WS を用いる場合, UT は SOAP 形式 の makeCallSessionRequest メッセージを sSCP に送信する。

SSCP はアクセス認可判定を行い, UT が AP と通信する権 限があるかどうかを確認し, UT が AP と通信する権限があ れば，UT および AP の SP を検索する。 SSCP は，2つの SP から UT および AP の両方で利用可能な SA を作成する。

次に, SSCP は, SIP 3PCC ${ }^{(19)}$ に準拠した方式で, SSCP が SA を付加した INVITE メッセージを作成・送信し, UT と AP 間の IPsec 通信セッションを確立する。

(3) IPsec 通信

仲介認証モデルでは，暗号化通信セッションが確立する と, UT と AP が直接暗号化通信を行う。

セキュア通信提供サービスでは, 図 7 に示したシーケン スに従って処理を行う。このとき, UT から AP にデータを 送信する場合, UT は AP と共有している SA が存在するか を確認し，当該 SA で指定されたアルゴリズムや鍵の值を用 いて暗号化した IPsec パケットを送信する。SA が存在しな い場合，データを破棄する。

また，AP は，UT から IPsec パケットを受信すると, UT と共有している SA が存在するかを確認し, 当該 SA で指定 されたアルゴリズムや鍵の值を用いて復号処理を行う。SA が存在しない場合および正しく復号できなかった場合に は，受信したパケットを破棄する。

(4) IPsec 通信セッション切断

仲介認証モデルでは, 確立している通信を切断する場合 にも, UT あるいは AP が TTP に要求して通信を切断する。

セキュア通信提供サービスでは, 図 8 に示すシーケンス に従って処理を行う。このとき, UT あるいは AP が, SSCP に SIP BYE メッセージを送信するか, sSCP の Parlay-X 3PCC WS を利用することで通信を切断する。

いずれの場合も SIP で規定された標準的なセッション切 断シーケンスに従っており, SIP BYEメッセージを受信した UT およびAP は, 対応する SA を削除する。これによって, 共有された SA がなくなり，暗号化通信が行えなくなる。

(5) セキュリティポリシー削除

仲介認証モデルでは, AP あるいはUTは, すべての通信 が終了すると，TTPに登録した SP を削除する。

セキュア通信提供サービスでは, 図 9 に示すシーケンス に従って処理を行う。このとき, AP あるいはUT が, 本文 が空の SIP MESSAGEメッセージを SSCP に送信することで 上記を実現する。SIP MESSAGEメッセージを受信した SSCP は，送信者（SIP-URI）のSP を削除する。

〈4·3〉 セキュアセッション制御サーバ (sSCP) の構成 SSCP は, NGN に接続されており, 以下の機能とデータベ 一ス（DB）を備える。

(1) SIP 通信機能 (SIP UA)

SIP UA は, SIP メッセージを受信・作成・処理し, SPM, B2B UA, 3PCC UA 等の上位の機能群に処理を振り分ける。

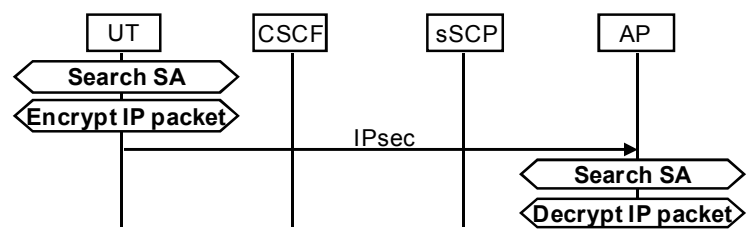

Fig. 7. IPsec communication

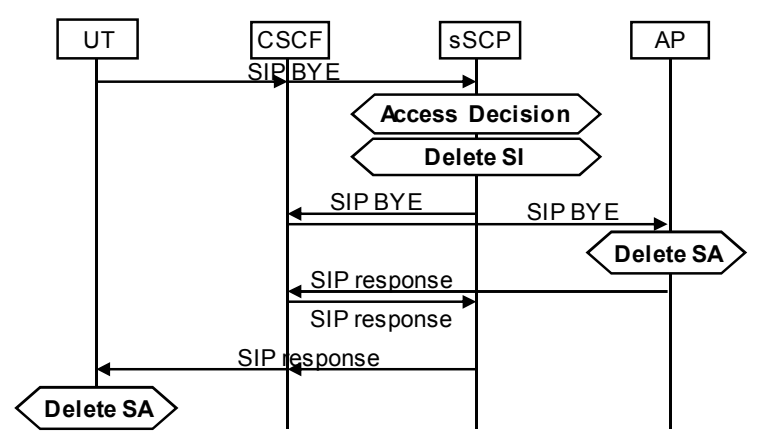

(a) IPsec session termination, initiated by SIP BYE message

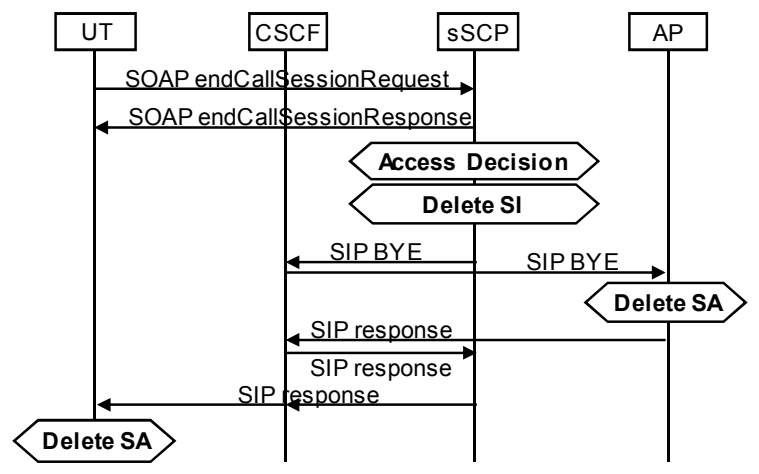

(b) IPsec session termination, initiated by Paray $-X$ WS

Fig. 8. IPsec session termination
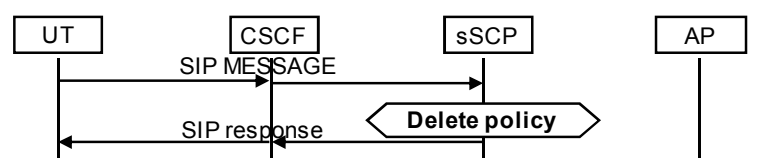

Fig. 9. Policy de-resistration

（2）セキュリティポリシー管理機能（SPM）

SPM は, 通信装置の認証と SP の登録・削除を行う SSCP 側の機能である。通信装置から受信した SP はポリシー情報 DB に格納する。

SIP MESSAGE メッセージをSIP UA が受信した場合に, 本機能が呼び出される。

( 3 ) Back-to-Back User Agent 機能 (B2B UA)

B2B UA は, SIP メッセージによるセッション確立および 切断を行う機能である。ポリシー情報 DB から SP を検索し, $\mathrm{SA}$ を作成する機能を持つ。

セッションを確立時に SA をセッション情報 DB に格納 し, 切断要求を受けると該当する SA をセッション情報 DB から削除する。 
(4) Third Party Call Control User Agent 機能（3PCC UA） 3PCC UA は, Parlay-X Third Party Call Web Serviceによる セッション確立および切断を行う機能である。Parlay-X Third Party Call Web Service で規定された Webサービスイン タフェース, SIP 3PCC 機能を実装するとともに，ポリシー 情報 DB から SP を検索し，SA を作成する機能を持つ。

セッションを確立時には SA をセッション情報 DB に格納 し, 切断要求を受けると該当する SA をセッション情報 DB から削除する。

（5）ポリシー情報 DB（Policy Info.DB）

UT や AP の SP を管理するデータベースである。

（6）セッション情報 DB（Session Info.DB）

UT や AP の間で現在確立している IPsec セッションに関 する情報を管理するデータベースである。表 3 に示した SA 情報のうち，暗号鍵およびハッシュ鍵を除く情報と，UT お よび AP と SSCP との間で確立している SIP セッションの識 別情報 (Call-ID) を関連付けて管理する。

〈4·4〉 通信装置 (UT, AP) の構成 UT および AP は, NGN もしくはインターネットに接続され, 以下の機能 および DB を備える。

(1) IPsec 通信機能

アプリケーションから IP パケットを受信すると, SADB を検索し，SAを適用して暗号化処理を行う。SADBに対応 する SA が登録されていない場合には, パケットを破棄する とともに，SSCにセッション確立を要求する。

ネットワークから IPsec パケットを受信すると, SADBを 検索し, SA を適用して復号処理を行う。SADBに対応する SA が登録されていない場合や正しく復号できない場合に は,パケットを破棄する。

(2) ポリシー登録機能 (SPR)

SPR は, 認証とSP の登録・削除を行う機能である。SSCP に認証を受けるために電子署名を作成する機能を持つ。

(3) セッション制御機能 (SSC)

SSC は, ユーザや IPsec 通信機能から要求を受けた場合に, SSCP に暗号化通信セッションの確立および切断を要求する 機能である。

また，CSCF から SIP INVITEメッセージを受信した場合 に, SIP メッセージに含まれる SA 情報を抽出し, SADB に 登録する機能や, SIP BYE メッセージを受信した場合に, SADB から該当する SA を削除する機能を持つ。

(4) SA データベース（SADB）

現在確立している IPsec セッションに関連する SA 情報を 格納するデータベースである。

\section{5. 評 価}

〈5·1〉要件への適合性 4 章で提案したセキュア通 信提供サービスを 3 章で示した要件の適合性について述べ る。

(1) アプリケーションプロトコルに非依存であること 本稿のセキュア通信提供サービスは, 暗号化通信プロト
コルとして IPsecを用いている。したがって, セキュア通信 提供サービスは, HTTP や FTP, RTP 等のアプリケーション プロトコルに依存せず，通信を保護することができる。さ らには，IP は NGN のベースプロトコルであり，NGN では アプリケーションプロトコルは必ず IP 上に実装される。

しかし，本稿のセキュア通信提供サービスは，IP マルチ キャストを利用するアプリケーションプロトコルには対応 できていない。しかし，本稿のセキュア通信提供サービス は，鍵交換に IKE 等ユニキャスト専用のプロトコルを用い ていないこと, および, 通信端末間で 1 つの SIP セッション を確立するのではなく, 通信端末と SSCP 間で 1 つずつ SIP セッションを確立していることから, グループ管理の機能 を追加することで IP マルチキャストを利用するアプリケー ションプロトコルにも対応できる可能性がある。

以上のように, 本稿のセキュア通信提供サービスは, NGN 上の任意のユニキャスト形式のアプリケーションプロトコ ルに対応している。

（2）セキュア通信セッションを高速に確立できること

本稿のセキュア通信提供サービスは, 仲介型認証モデル に基づき，ユーザによるパスワードの入力や暗号演算など のために時間を必要とする認証処理をすべての処理に先立 って実施する。

また，UT や AP 間で SA を計算するのではなく, SSCP が $\mathrm{SA}$ を作成・配付する。

以上により，セキュア通信セッションを確立する際に時 間がかかる処理を省略することができるため, セキュア通 信セッションを高速に確立できる。

（3）通信データの機密性を保護する機能

本稿のセキュア通信提供サービスは, 通信データの機密 性保護をIPsecにより実現する。

しかし，本稿のセキュア通信提供サービスは，SA $\mathrm{SSCP}$ で作成して UT や AP に配付するため, SA を不正に入手す ることで通信データの盗聴が可能となる可能性がある。

$\mathrm{SA}$ の不正入手方法としては, $\mathrm{sSCP}$ の不正アクセスによ り SA を入手する方法と, $\mathrm{SSCP}$ から UT または AP に送信さ れるメッセージを盗聴して SA を入手する方法とが考えら れる。

しかし, 前者に対しては, SSCPではSA, 特に秘密情報で ある暗号鍵やハッシュ鍵を保持しないことにより不正入手 を防止できる。すなわち, SSCP では秘密情報を作成するも のの, SA を配布した後は保持せずに, 破棄するようにする。

次に, 後者については, sSCP-通信装置間の通信には NGN のSIP 通信を用いており, NGN 内の通信は安全に保護され る。すなわち, 後者の問題は, インターネット区間での CSCF と UT または AP との間の SIP メッセージの機密性が担保で きるか，に帰着できる。NGN のセッション管理機能である IMS では, 通信端末と CSCF との間は IPsecによって暗号化 することが規定されており, インターネット区間でも CSCF と通信装置間も IPsecによって保護される。

以上から, 本稿のセキュア通信提供サービスは, SA を不 
正に入手することは不可能であり, 通信データの機密性保 護が実現できている。したがって，本稿のセキュア通信提 供サービスは通信データの盗聴防止を実現できる。

(4) 通信データの完全性を検証する機能

通信データの完全性検証についても, ( 3 )の通信データの 機密性保護と同様であり, 本稿のセキュア通信提供サービ スは通信データの完全性検証が実現できている。したがっ て, 本稿のセキュア通信提供サービスは通信データの改ざ ん・破壊防止を実現できる。

（5）通信先が正当な相手であるかを認証する機能 本稿のセキュア通信提供サービスでは, UT および AP は, SP を登録する際に電子署名により SSCP に認証を受ける。 このとき, SSCP は, 電子署名によって確認されたユーザと, 登録要求メッセージの SIP-URI とを関連付ける。以降, 同 じ送信者 (SIP-URI) から受信する SIP メッセージは電子署 名が付加されていなくてもすでに認証済であると判断す る。

NGN では, NBE が信頼できない通信相手からの攻撃を防 御する。そのため, 不正者が送信者の SIP-URI を詐称した SIP メッセージを送信しても, NBE が当該メッセージを SSCP に転送しないよう防御する。これにより, SIP メッセ ージの送信元が正当であることを保証できる。

また, 本稿のセキュア通信提供サービスでは, SSCP が SIP INVITE メッセージを送信する相手（UT または AP）は，上 記関連付けが行われている相手に限定される。これにより, SIP メッセージの送信先が正当であることを保証できる。

以上により, 本稿のセキュア通信提供サービスでは, UT や AP になりすまして通信を行うことは不可能であり, 成り すましによる通信データの詐取や不正な通信先への誘導を 防止できる。

しかし，ネットワーク切断が発生した場合等，ユーザが ログアウトしたにも関わらず，SSCP にはログアウトの通知 が届かないような場合が想定される。このような場合, sSCP ではポリシーの削除漏れが発生し，未認証のユーザが認証 済みであると誤判定されてしまう可能性がある。このよう な場合への対応として, sSCP でNGN のユーザ管理機能 (プ レゼンス機能）と連携し，NGN でのユーザ状態の変更を取 得してポリシーを更新することが必要である。

〈5·2〉 既存手法との比較 暗号化通信では，ユーザ によるパスワードの入力や暗号演算処理が必要となる, 認 証処理と暗号演算処理による暗号鍵の共有処理（SA 共有処 理）が通信セッション確立時の性能低下の大きな要因とな る。

$m$ 台の AP がそれぞれ $n$ 台の UT と通信する（1 台の UT は 1 台の AP としか通信しない) クライアント・サーバモデ ルと, $n$ 台の UT が相互に通信する P2P モデルに提案手法や 従来手法（IKE 方式および SIP DIAL-UP 方式）を適用した 場合の, UT1 台毎, AP1 台毎, システム全体での認証処理 回数と SA 共有処理回数の比較を表 4 に示す。

表 4 ではに示したように, サーバ・クライアントモデル
において IKE 方式や SIP DIAL-UP 方式を適用した UT では, 通信セッション確立時に認証処理や SA 共有処理をそれぞ れ 1 回ずつ必要とする。一方, 提案手法を適用した UT は, 通信セッション確立に先立って SSCP との間で行われる認証 処理（事前認証処理: preauthetnication）が 1 台毎に 1 回ずつ 必要となるが, 通信セッション確立時には認証処理および 暗号演算処理を必要とする SA 共有処理は不要である。

したがって, この場合でも SA 共有処理が不要である分, 提案手法の方が通信セッション確立コストを抑えられる。

一方, サーバ・クライアントモデルにおいて IKE 方式や SIP DIAL-UP 方式を適用した AP では， $m$ 台の UT と通信セ ッション確立するために認証処理や SA 共有処理をそれぞ れ $m$ 回ずつ必要とする。一方, 提案手法を適用した AP は, 通信セッション確立に先立って sSCP との間で事前認証処理 が 1 台毎に 1 回ずつ必要となるが, 通信セッション確立時 には認証処理および暗号演算処理を必要とする SA 共有処 理は不要である。

したがって, 複数の UT と通信する AP の場合には, 提案 手法の方が通信セッション確立コストを抑えられる。

同様に, P2P 通信モデルにおいて IKE 方式や SIP DIAL-UP 方式を適用した UT では, UT の数 $(=n)$ の認証処理・SA 共有処理が必要となるが, 提案手法を適用した場合には, 通信セッション確立に先立って $\mathrm{sSCP} と の$ 閒で事前認証処理 が UT1 台毎に 1 回ずつ必要となるのみである。

したがって, P2P 通信モデルにおいては, 提案手法の方が 通信確立コストを抑えられる。

システム全体での認証処理・SA 共有処理の数を比較する と, サーバ・クライアントモデルでは IKE 方式や SIP DIAL-UP 方式を適用した場合にはAP と UT の数の積に比例 する $(O(m n))$ が，提案手法を適用した場合，AP と UT の 数の和に比例する $(O(m+n))$ 。

Table 4. Comparison with existing methods

\begin{tabular}{|c|c|c|c|c|c|}
\hline \multicolumn{3}{|c|}{ Process } & IKE & $\begin{array}{c}\text { SIP } \\
\text { DIAL-UP }\end{array}$ & $\begin{array}{c}\text { Proposed } \\
\text { method }\end{array}$ \\
\hline \multirow{9}{*}{ 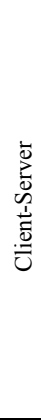 } & \multirow{3}{*}{ 与 } & Preauthentication & $\mathbf{0}$ & 1 & 1 \\
\hline & & Authentication & 1 & 1 & $\mathbf{0}$ \\
\hline & & Negotiation of SA & 1 & 1 & $\mathbf{0}$ \\
\hline & \multirow{3}{*}{ \& } & Preauthentication & $\mathbf{0}$ & 1 & 1 \\
\hline & & Authentication & $\mathrm{n}$ & $\mathrm{n}$ & $\mathbf{0}$ \\
\hline & & Negotiation of SA & $\mathrm{n}$ & $\mathrm{n}$ & $\mathbf{0}$ \\
\hline & \multirow{3}{*}{ 要 } & Preauthentication & $\mathbf{0}$ & $\mathrm{n}+\mathrm{m}$ & $\mathrm{n}+\mathrm{m}$ \\
\hline & & Authentication & $\mathrm{nm}$ & $\mathrm{nm}$ & $\mathbf{0}$ \\
\hline & & Negotiation of SA & $\mathrm{nm}$ & $\mathrm{nm}$ & $\mathbf{0}$ \\
\hline \multirow{6}{*}{$\hat{\mathbf{\Lambda}}$} & \multirow{3}{*}{5} & Preauthentication & $\mathbf{0}$ & 1 & 1 \\
\hline & & Authentication & $\mathrm{n}$ & $\mathrm{n}$ & $\mathbf{0}$ \\
\hline & & Negotiation of SA & $\mathrm{n}$ & $\mathrm{n}$ & $\mathbf{0}$ \\
\hline & \multirow{3}{*}{ 吾 } & Preauthentication & $\mathbf{0}$ & $\mathrm{n}$ & $\mathrm{n}$ \\
\hline & & Authentication & $\mathrm{n}^{2}$ & $\mathrm{n}^{2}$ & $\mathbf{0}$ \\
\hline & & Negotiation of SA & $\mathrm{n}^{2}$ & $\mathrm{n}^{2}$ & $\mathbf{0}$ \\
\hline
\end{tabular}


同様に，P2P モデルでは，IKE 方式や SIP DIAL-UP 方式は $\mathrm{UT}$ の数の 2 乗に比例する $\left(O\left(n^{2}\right)\right)$ が, 提案手法では UT の 数に比例する $(O(n))$ 。

上述のように, 提案手法は, 従来手法と比較すると, 通 信装置が多く，かつメッシュ状に通信する場合に特に有効 であると考えられる。

〈5·3〉実装上の考慮点 提案手法を通信装置に実装 する場合には, IPsec 通信機能はオペレーティングシステム （OS）が標準で提供する機能を利用し，SPR および SSC 機 能を実装したソフトウェアを IKE 機能の代わりに導入する ことで実現できる。

しかし, OS が標準提供する IPsec 通信機能の中には，必 ず IKE によって鍵交換を実施するものが存在する。このよ うな IPsec 通信機能では提案手法を適用できないため, 提案 手法を実装する場合, IPsec 通信機能および SADB を実装し た仮想ネットワークドライバを用い，OS が標準提供する IPsec 通信機能は使用しないようにする必要がある。

また, 提案手法では SP や電子署名, SA を SIP メッセー ジに格納するため, SIP メッセージのサイズが 1IP パケット よりも大きくなる可能性がある。そのため, SIP の下位プロ トコルとして TCP を用いることが望ましい。

さらに, 提案手法では, SSCP が単一障害点となる。莫大 な数の UT や AP が一斉に認証・セキュリティポリシー登録 を実施したり, 接続要求を行ったりすると, SSCP に過大な 負荷が発生する可能性がある。このため, 圥長化等によっ て可用性を向上させることが必要である。

\section{6. まとめ}

本稿では，NGN とインターネットの相互接続環境におい て, 不特定多数の通信装置に対して暗号化通信セッション を設定・制御する，セキュア通信提供サービスを提案した。

本稿のセキュア通信提供サービスは, SIP を制御プレーン のプロトコルとして用い, NGN のセッション確立機能

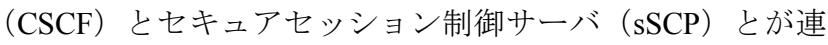
携して信頼できる第三者（TTP）の役割を果たすことで，ユ ーザプレーンを sSCP が制御し，仲介型認証モデルを実現す る。仲介型認証モデルに基づくことで， SSCP による事前認 証と, NGN が保護している SIP セッションでの SA 配付と により通信装置間で安全かつ高速な鍵共有を実現できる。 この結果, NGN とインターネットの相互接続環境で暗号化 通信路を高速に確立させることができるため，従来のクラ イアント・サーバ型の通信形式だけでなく, 端末同士が通 信しあう P2P 型の通信形式にも容易に対応できる。

今後は, セキュア通信提供サービスの性能評価および sSCP でNGN のユーザ管理機能と連携し，NGN でのユーザ 状態の変更を取得してポリシーを更新する機能を検討して いく必要があると考えている。

さらには，NGN の放送系のアプリケーションでの利用が 見込まれる，IP マルチキャストを利用できるようにするた めの拡張等も検討していく予定である。

\section{謝 辞}

本稿は, 情報通信研究機構から委託を受けた「次世代ネ ットワーク（NGN）基盤技術の研究開発」の研究成果を含 んでいる。関係各位のご協力に感謝する。

(平成 21 年 8 月 11 日受付, 平成 22 年 4 月 18 日再受付)

\section{文献}

(1) T. Fukazawa, T. Nisase, M. Kawashima, T. Hariu, and Y. Oshima : "Safe and Secure Services Based on NGN", IEICE Trans. on Information and Systems, Vol.E91-D, No.5, pp.1226-1233 (2008-5)

(2) S. Kent and R. Atkinson : RFC2401, "Security Architecture for the Internet Protocol", IETF (1998-11)

( 3 ) T. Dierks and C. Allen : RFC2246, "The TLS Protocol Version 1.0", IETF (1999-1)

(4) J. Rosenberg, H. Schulzrinne, G. Camarillo, A. Johnston, J. Peterson, R. Sparks, M. Handley, and E. Schooler : RFC3261, "SIP: Session Initiation Protocol", IETF (2002-6)

(5) M. Kawashima, S. Mizuno, and J. Kato : "Architecture for broadband and mobile VPN over NGN", Innovations in NGN: Future Network and Services 2008 (K-INGN 2008), pp.187-194 (2008-5)

（6）東日本電信電話（株）「「IP 通信網サービスのインタフェース 第三 分冊 (第 5 版)」, pp.37-64, pp.82-101 (2009-2)

( 7 ) ETSI TS 187001 : "Telecommunications and Internet converged Services and Protocols for Advanced Networking (TISPAN); NGN SECurity (SEC); Requirements", ETSI (2006-3)

(8) Recommendation ITU-T Y.2701 : "Security requirements for NGN release 1", ITU-T (2007-4)

(9) L. Zhang and K. Zhao : "Study on Security of Next Generation Network", IEEE International Conference on Service Operations and Logistics, and Informatics, 2008, pp.538-541 (2008-10)

(10) Z. S. Khan, M. Sher, K. Rashid, and I. Razzak : "Towards Security and Enrichment of the IP Multimedia Subsystem Based Multiparty Conference", Proc. of the International MultiConference of Engineers and Computer Scientists 2009 (IMECS 2009), Hong Kong (2009-3)

(11) A. Awais, M. Farooq, and M. Y. Javed : "Attack analysis \& bio-inspired security framework for IPMultimedia subsystem”, GECCO '08: Proceedings of the 2008 GECCO conference companion on Genetic and evolutionary computation, pp.2093-2098 (2008-7)

(12) ITU-T Recommendation I.322 : "Generic protocol reference model for telecommunication networks", ITU-T (1999-2)

(13) ITU-T Recommendation X.1152 : "Secure end-to-end data communication techniques using trusted third party services", ITU-T (2008-5)

(14) T. Kaji, O. Takata, K. Hoshino, T. Fujishiro, and S. Tezuka : "A Model for Establishing Secure Communication in Secure Service Platform", IPSJ SIG Notes, CSEC-033, pp.151-156 (2005-3) (in Japanese) 鍛 忠司・高田 治・星野和義・藤城孝宏・手塚 悟: 「セキュアサ ービスプラットフォームにおけるセキュア通信確立モデル」, 情処研 報, CSEC-033, pp.151-156 (2005-3)

(15) T. Kaji, K. Hoshino, T. Fujishiro, O. Takata, A. Yato, K. Takeuchi, and S. Tezuka : "TLS handshake method based on SIP", Proc. of the International Multiconference on Computer Science and Information Technology, pp.467-475 (2006-11)

(16) ETSI, Draft ETSI ES 202 504-2 v0.0.5 : "Open Service Access(OSA); Parlay X Web Services: Part 2: Third Party Call (Parlay X 3)", ETSI (2007-6)

(17) T. Nisase : "Achieving Security in the NGN", NTT Technical Review, Vol.20, No.9 (2008-9) (in Japanese)

仁佐瀬岡美 :「NGNにおけるセキュリティの実現」, NTT 技術ジャー ナル, Vol.20, No.9 (2008-9)

(18) E. B. Campbell, J. Rosenberg, H. Schulzrinne, C. Huitema, and D. Gurle : RFC3428, "Session Initiation Protocol (SIP) Extension for Instant Messaging", IETF (2002-12)

(19) J. Rosenberg, J. Peterson, H. Schulzrinne, and G. Camarillo : RFC3725, "Best Current Practices for Third Party Call Control (3pcc) in the Session Initiation Protocol (SIP)", IETF (2004-4) 


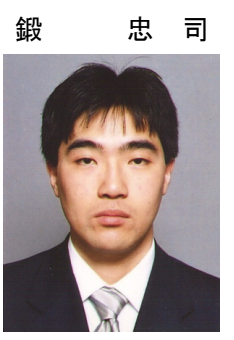

（非会員） 1996 年 3 月大阪大学基礎工学研究科 物理系専攻情報工学分野博士前期課程修了。同 年 日立製作所入社，システム開発研究所配属。 以来，企業情報システム，分散システム，モバ イルシステム, ネットワークサービス等に対す る認証基盤やセキュリティソリューションの 研究に従事。工学修士。IEEE CS 会員。

\section{藤 城 孝 宏}

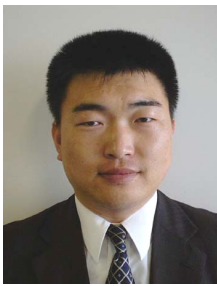

（非会員）1993 年慶應義塾大学理工学研究科電 気工学専攻修士課程修了。同年（株）日立製作 所入所。マイクロエレクトロニクス機器開発研 究所を経て, 現在，システム開発研究所第七部 勤務。2009 年より, 慶應義塾大学理工学研究科 開放環境科学専攻後期博士課程在学。ネットワ ーク管理システム等の研究を経て, 現在, セキ ユリティシステム, 特に電子認証の研究開発に 従事。電子情報通信学会員。

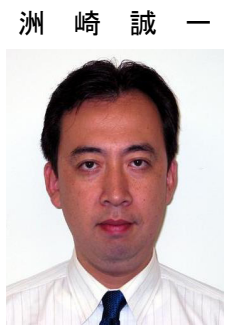

川井恵理

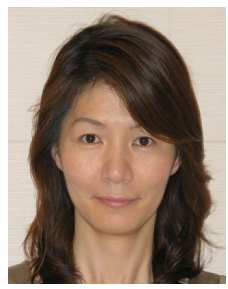

（非会員）1996 年 3 月東京理科大学大学院情報 科学専攻修了。同年 日立製作所入社。入社以来, IP 通信サービスに関するサーバシステム，およ びネットワークソリューション開発に従事。

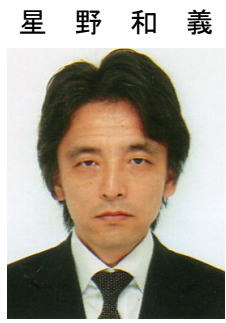

（非会員）1997 年 3 月名古屋大学工学研究科博 士課程後期過程修了。博士 (工学)。同年日立 製作所入社。入社以来, ネットワークシステム やセキュリティシステムの研究開発，現在，ネ ットワークソリューション開発やシステム開 発などに従事。

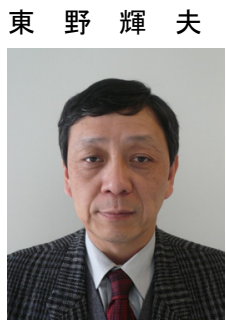

（非会員） 1979 年 3 月大阪大学卒業。1984 年 3 月同大学院博士後期課程修了。同年同大助手。 現在, 大阪大学大学院情報科学研究科教授。分 散システム, モバイルコンピューティング, 通 信プロトコルなどの研究に従事。情報処理学会 フェロー，IEEE Senior Member，電子情報通信 学会, ACM 各会員。 